\begin{tabular}{ll|l} 
Case Reports in & \multicolumn{2}{c}{ Case Rep Gastroenterol 2017;11:473-479 } \\
\cline { 2 - 3 } Gastroenterology & $\begin{array}{l}\text { DOI: 10.1159/000479551 } \\
\text { Published online: August 17, } 2017\end{array}$ & $\begin{array}{l}\text { ( 2017 The Author(s) } \\
\text { Published by S. Karger AG, Basel } \\
\text { www.karger.com/crg }\end{array}$ \\
\cline { 2 - 3 } & $\begin{array}{l}\text { This article is licensed under the Creative Commons Attribution-NonCommercial } 4.0 \\
\text { International License (CC BY-NC) (http://www.karger.com/Services/OpenAccessLicense). } \\
\text { Usage and distribution for commercial purposes requires written permission. }\end{array}$
\end{tabular}

\title{
Celiac Disease Associated with a Benign Granulomatous Mass Demonstrating Self-Regression after Initiation of a Gluten-Free Diet
}

\author{
Abhinav Tiwari ${ }^{\mathrm{a}} \quad$ Himani Sharma $^{\mathrm{a}}$ Khola Qamar $^{\mathrm{b}}$ Zubair Khan ${ }^{\mathrm{a}}$ \\ Umar Darr ${ }^{a} \quad$ Anas Renno ${ }^{a} \quad$ Ali Nawras ${ }^{b}$ \\ ${ }^{a}$ Department of Internal Medicine, University of Toledo Medical Center, Toledo, $\mathrm{OH}, \mathrm{USA}$; \\ ${ }^{\mathrm{b}}$ Department of Gastroenterology, University of Toledo Medical Center, Toledo, $\mathrm{OH}, \mathrm{USA}$
}

\section{Keywords}

Celiac disease · Granulomatous mass · Gluten-free diet

\begin{abstract}
Celiac disease is a chronic immune-mediated enteropathy in which dietary gluten induces an inflammatory reaction predominantly in the duodenum. Celiac disease is known to be associated with benign small bowel thickening and reactive lymphadenopathy that often regresses after the institution of a gluten-free diet. A 66-year-old male patient with celiac disease presented with abdominal pain and diarrheal illness. Computerized tomography of the abdomen revealed a duodenal mass. Endoscopic ultrasound-guided fine needle aspiration of the mass revealed bizarre stromal cells which represent a nonspecific tissue reaction to inflammation. This inflammatory mass regressed after the institution of a gluten-free diet. This case report describes a unique presentation of celiac disease in the form of a granulomatous selfregressing mass. Also, this is the first reported case of bizarre stromal cells found in association with celiac disease. In addition to lymphoma and small bowel adenocarcinoma, celiac disease can present with a benign inflammatory mass, which should be serially monitored for resolution with a gluten-free diet.




\section{Introduction}

Celiac disease (CD) is a chronic small intestinal, immune-mediated enteropathy that is precipitated by dietary gluten in genetically predisposed individuals. It is well documented that patients with CD have an increased risk of developing small bowel lymphoma with lymphadenopathy [1], which accounts for half to two-thirds of the malignancies found in CD $[2,3]$. However, CD can also be associated with benign small bowel thickening and reactive lymphadenopathy [4]. These reactive changes do not always represent malignancy and often regress after the institution of a gluten-free diet (GFD) as the inciting antigen is removed [5-7].

Here we present the case of a patient with CD who was diagnosed with having a duodenal mass on computerized tomography (CT). Due to the concern for malignancy associated with $\mathrm{CD}$, an endoscopic ultrasound was performed and the mass was found to be arising from the outer duodenal wall. Fine needle aspiration revealed bizarre stromal cells (BSCs) without any evidence of lymphoma or any other malignancy. After starting a strict GFD, the mass was found to be regressing on follow-up imaging scans.

\section{Case Presentation}

A 66-year-old male patient with a history of CD presented to our clinic with chronic abdominal pain and diarrhea. He had been experiencing intermittent crampy, diffuse abdominal pain associated with 3-4 daily episodes of loose bowel movements for the previous 3 months. Since the diagnosis of CD 5 years earlier, he had intermittently been adherent to a GFD. On questioning, he stated that he had been completely nonadherent to GFD for the previous 5 months. His weight had decreased from 175 to $165 \mathrm{lb}$ (5.7\% loss) over the previous 3 months.

A physical examination showed normal results except for mild diffuse abdominal tenderness. A laboratory workup revealed a white blood cell count of $7,900 / \mu \mathrm{L}$ and a hemoglobin level of $13.2 \mathrm{~g} / \mathrm{dL}$, with the remainder of the parameters within normal limits. Stool Clostridium difficile PCR and ova, parasites, and cultures were all negative. Celiac serology was found to be positive for IgA antiendomysial antibodies (titer 1:160) and IgA tissue transglutaminase ( 87 positive $>8$ ), reflecting his dietary noncompliance.

A CT scan of the abdomen showed a $5 \times 4 \mathrm{~cm}$ mass which seemed to be arising from the second part of the duodenum (Fig. 1). It was unclear if it was arising from the duodenum or was a mesenteric node close to the wall. Given this uncertainty, an esophagogastroduodenoscopy was performed, which revealed duodenal mucosal atrophy; however, no mass was seen invading the lumen. Endoscopic ultrasound revealed a hypoechoic, poorly demarcated, heterogeneous $53 \times 42 \mathrm{~mm}$ mass which was thought to be arising from the duodenal wall at the junction of the second and third part. Fine needle aspiration was performed, and histology revealed clusters of epithelioid histiocytes with nucleomegaly, nuclear pleomorphism in a background of macrophages, and multinucleate giant cells (Fig. 2, Fig. 3). This finding was consistent with a reactive inflammatory mass comprising BSCs. There was no evidence of systemic granulomatous diseases such as sarcoidosis, tuberculosis, or fungal infection in this patient.

It was concluded that an inflammatory reaction because of uncontrolled CD resulted in the formation of this walled-off inflammatory mass. It was decided to monitor this mass with periodic CT scans, and the patient was advised to strictly adhere to a GFD. Follow-up CT 
scans of the abdomen at 9 and 16 months revealed that the mass had shrunken to $3 \times 3 \mathrm{~cm}$ and $1 \times 1 \mathrm{~cm}$ (Fig. 4), respectively. The patient reported strict adherence to the GFD during this period and reported no recurrence of symptoms of the disease.

\section{Discussion}

CD is a chronic small intestinal, immune-mediated enteropathy that is precipitated by dietary gluten. This chronic immune system stimulation causes lymphoid hyperplasia and bowel epithelial atrophy. It is well known that there is an increased risk of lymphoproliferative disease and gastrointestinal cancer in patients with CD [1-3]. The BioMed European Working Group on Celiac Disease and Malignancy reviewed data from 10 countries and reported that there was a 2.6-fold increase in the prevalence of CD among 1,446 patients with non-Hodgkin lymphoma (NHL) compared with 9,659 control subjects [8]. Conversely, a prospective study showed that patients with CD have a 3.1-fold increased risk of NHL [9]. Abdominal CT scanning may reveal mesenteric lymphadenopathy in patients with CD; however, such lymphadenopathy is common in active $\mathrm{CD}$ and does not, by itself, indicate a need for investigation to exclude NHL. Often the lymphadenopathy is reactive, regressing after the institution of a GFD, since the inciting antigen is removed [5-7].

Other cancers, particularly of the oropharynx, esophagus, and small intestine, account for one-third of the malignancies associated with CD, particularly in patients older than 50 years. A Swedish population-based cohort study reported that there is also an elevated risk for small intestinal cancer (standardized incidence ratio 10) including adenocarcinomas in patients with CD [10].

In our patient, a CT scan of the abdomen revealed the heterogeneously appearing mass, which could have been arising from the duodenal wall. As there was a concern for malignancy, a further workup seemed reasonable. Esophagogastroduodenoscopy revealed that the mass was not invading the lumen of the gut wall, and endoscopic ultrasound confirmed this observation. Histology of the mass was consistent with features of BSCs, showing clusters of epithelioid histiocytes with nucleomegaly, nuclear pleomorphism in a background of macrophages, and multinucleate giant cells.

BSCs are atypical stromal cells which have been noted in many different organs (e.g., the respiratory tract, urinary bladder, endometrium, prostate, and gut). In the gut, these cells have been found to be associated with conditions such as ischemic colitis, reflux esophagitis, esophageal polyps, gastric ulcers, granulation tissue near surgical anastomoses, and pseudopolyps of inflammatory bowel disease [11-13]. These are large cells which may be spindled, stellate, or epithelioid and have vesicular nucleomegaly, nuclear pleomorphism, and multinucleation [14]. To the best of our knowledge, BSCs have never been reported to be associated with CD. BSCs are thought to represent a nonspecific tissue reaction to injury, since they have been consistently reported to occur at the sites involved in the reparative process and chronic inflammation. These cells are often mentioned as resembling cells infected by CMV or ganglion cells [12]. Although not performed in our case, BSCs consistently show positive immunohistochemistry for vimentin [14]. The histogenesis of BSCs is likely related to the degenerative effects of inflammatory or hypoxia-induced changes in fibro- or myofibroblastic cells [13]. In patients with CD, dietary gluten fractions induce an inflammatory reaction, primarily in the upper small intestine, characterized by infiltration of chronic inflammatory cells into the lamina propria and the epithelium [15]. 
In our patient, chronic inflammatory changes in the gut wall resulted in the formation of a reactive inflammatory mass with features of BSCs on histology. Clinical improvement is usually seen within days or weeks after the elimination of gluten, though histologic recovery may take months or even years and may even be incomplete. Lee et al. [16] reported that in patients with CD who had been on a GFD for a mean of 8.5 years, histology showed a reduction in the mean intraepithelial lymphocyte count (from 61 to 38), and the crypt-to-villous ratio also improved, even if only $21 \%$ of the patients had a normal duodenal mucosal histology. Elimination of dietary gluten in our patient caused the inflammation to subside, resulting in regression of the granulomatous mass. This was reassuring, as negative biopsies do not completely eliminate the possibility of lymphoma due to sampling error.

In conclusion, this is a unique case of $\mathrm{CD}$ presenting with a duodenal mass secondary to a chronic inflammatory reaction in the bowel wall. This is also the first reported case of BSCs associated with CD. In addition to lymphoma and small bowel adenocarcinoma, CD can present with a benign inflammatory mass, which should be serially monitored for resolution with a GFD.

\section{Statement of Ethics}

Approval from an ethics committee was not required in this case, as this is a case report. We have obtained written informed consent from the patient to publish this report.

\section{Disclosure Statement}

The authors declare that they have no competing interests.

\section{References}

1 Freeman H, Lemoyne M, Pare P: Coeliac disease. Best Pract Res Clin Gastroenterol 2002;16:37-49.

-2 Corrao G, Corazza GR, Bagnardi V, Brusco G, Ciacci C, Cottone M, et al: Mortality in patients with coeliac disease and their relatives: a cohort study. Lancet 2001;358:356-361.

-3 Askling J, Linet M, Gridley G, Halstensen TS, Ekström K, Ekbom A: Cancer incidence in a populationbased cohort of individuals hospitalized with celiac disease or dermatitis herpetiformis. Gastroenterology 2002;123:1428-1435.

4 Martel J, Sussman DA, Goldberg RI, Valantas M, Barkin JS: Benign small bowel thickening and lymphadenopathy: a manifestation of celiac disease. Dig Dis Sci 2009;54:902-905.

5 de Boer WA, Maas M, Tytgat GN: Disappearance of mesenteric lymphadenopathy with gluten-free diet in celiac sprue. J Clin Gastroenterol 1993;16:317-319.

-6 Al-Kawas FH, Murgo A, Foshag L, Shiels W: Lymphadenopathy in celiac disease: not always a sign of lymphoma. Am J Gastroenterol 1988;83:301-303.

-7 Yousif E, Gupta R, Gelzayd E, Osher D, Maas L: Lymphadenopathy in celiac sprue, not necessarily a malignant disease. J Clin Gastroenterol 1998;27:82-84.

-8 Cerf-Bensussan N, Cellier C, Hayman M, Brousse N, Schmitz J: Coeliac disease: an update on facts and questions based on the 10th International Symposium on Coeliac Disease. J Pediatr Gastroenterol Nutr 2003;37:412-421.

-9 Catassi C, Fabiani E, Corrao G: Risk of non-Hodgkin lymphoma in celiac disease. JAMA 2002;287:14131419.

10 Askling J, Linet M, Gridley G, Barbato M, De Renzo A, Carella AM, et al: Cancer incidence in a populationbased cohort of individuals hospitalized with celiac disease or dermatitis herpetiformis. Gastroenterology 2002;123:1428-1435.

11 Serra S, Chetty R: Bizarre stromal cells in ischemic bowel disease. Ann Diagn Pathol 2005;9:193-196. 


\section{Case Reports in Gastroenterology}

\begin{tabular}{l|l}
\hline Case Rep Gastroenterol 2017;11:473-479 \\
\hline DOI: 10.1159/000479551 & $\begin{array}{l}\text { ○ 2017 The Author(s). Published by S. Karger AG, Basel } \\
\text { www.karger.com/crg }\end{array}$ \\
\hline
\end{tabular}

Tiwari et al: Celiac Disease Associated with a Benign Granulomatous Mass Demonstrating Self-Regression after Initiation of a Gluten-Free Diet

12 Shekitka KM, Helwig EB: Deceptive bizarre stromal cells in polyps and ulcers of the gastrointestinal tract. Cancer 1991;67:2111-2117.

13 Dhungel BM, De Petris G: Bizarre stromal cells in the esophagus: report of 2 cases and literature review. Int J Surg Pathol 2013;21:368-372.

14 De Petris G, Leung ST: Pseudoneoplasms of the gastrointestinal tract. Arch Pathol Lab Med 2010;134:378-392.

15 Green PH, Cellier C: Celiac disease. N Engl J Med 2007;357:1731-1743.

-16 Lee SK, Lo W, Memeo L, Rotterdam H, Green PH: Duodenal histology in patients with celiac disease after treatment with a gluten-free diet. Gastrointest Endosc 2003;57:187-191.

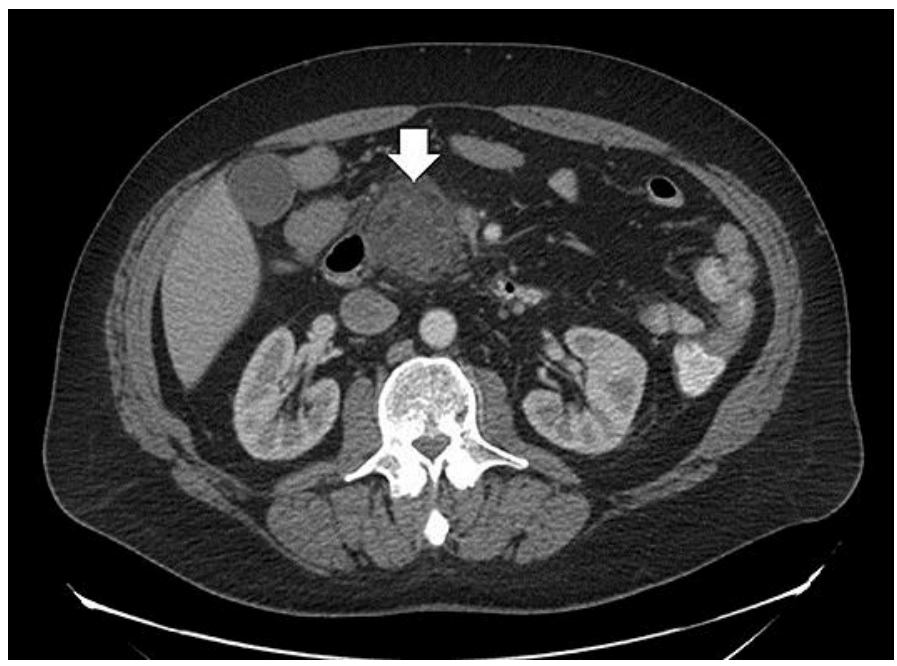

Fig. 1. Computerized tomography of the abdomen showing a $5 \times 4 \mathrm{~cm}$ mass arising from the second part of the duodenum (arrow). 


\section{Case Reports in Gastroenterology}

\begin{tabular}{l|l}
\hline Case Rep Gastroenterol 2017;11:473-479 \\
\hline DOI: 10.1159/000479551 & $\begin{array}{l}\text { ○ } 2017 \text { The Author(s). Published by S. Karger AG, Basel } \\
\text { www.karger.com/crg }\end{array}$
\end{tabular}

Tiwari et al.: Celiac Disease Associated with a Benign Granulomatous Mass Demonstrating Self-Regression after Initiation of a Gluten-Free Diet

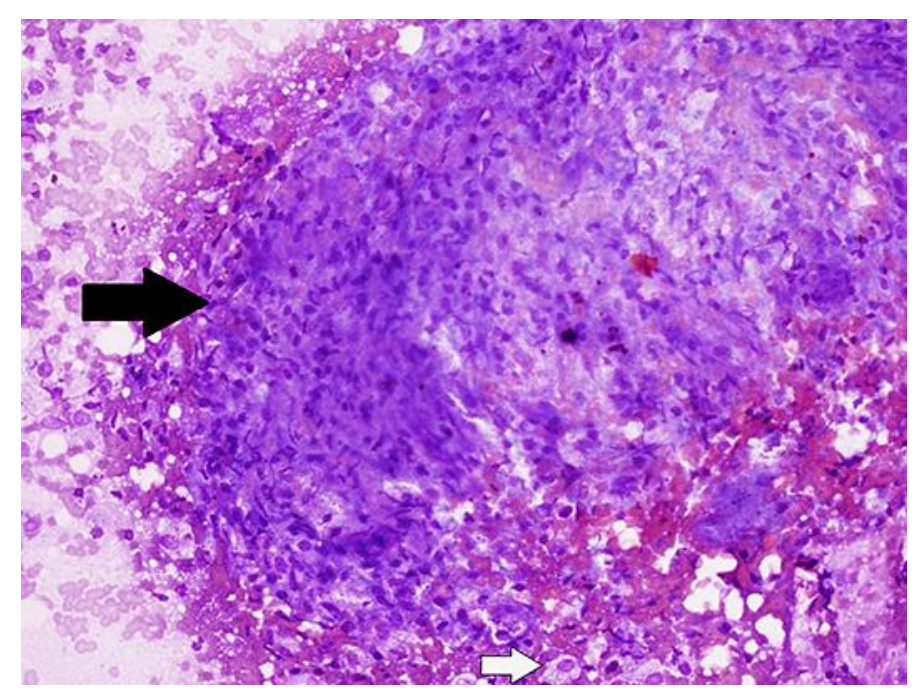

Fig. 2. A cluster of epithelioid histiocytes (black arrow) with nucleomegaly and nuclear pleomorphism. Also, large bizarre stromal cells (white arrow) with nucleomegaly and amphophilic cytoplasm can be seen in the inflammatory background. Original magnification, $\times 400$.

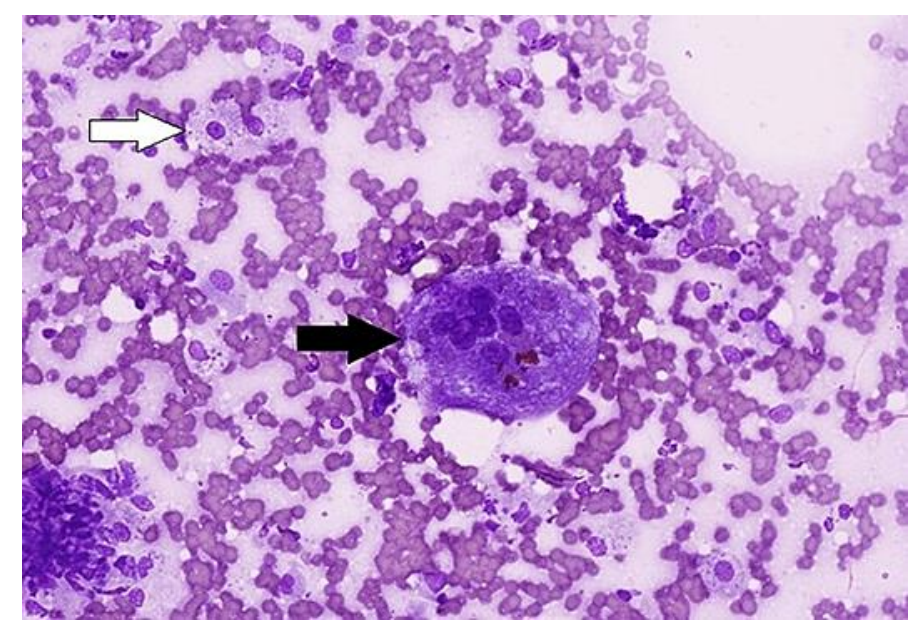

Fig. 3. A large multinucleate giant cell (black arrow) can be seen along with a bizarre stromal cell (white arrow). Original magnification, $\times 400$. 
Tiwari et al.: Celiac Disease Associated with a Benign Granulomatous Mass Demonstrating Self-Regression after Initiation of a Gluten-Free Diet

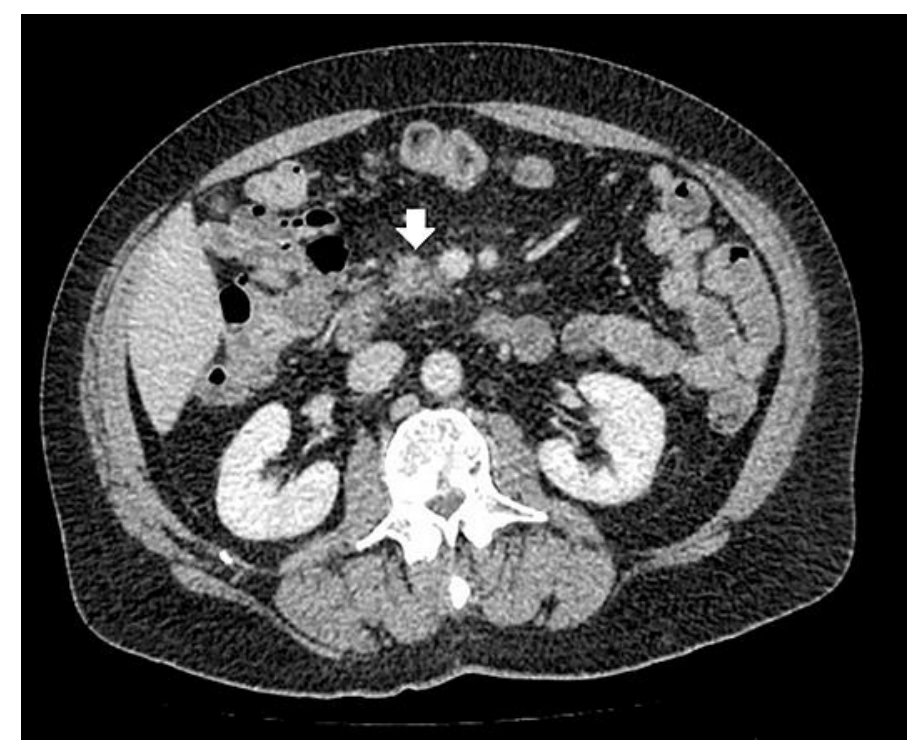

Fig. 4. Computerized tomography of the abdomen at the 16-month follow-up showing intermediary regression of the mass, now measuring $1 \times 1 \mathrm{~cm}$ (arrow). 